\title{
An unexpected gene cluster for downstream degradation of alkylphenols in Sphingomonas sp. strain TTNP3
}

\author{
Boris A. Kolvenbach • Hyazinth Dobrowinski • Jan Fousek • Cestmir Vlcek • \\ Andreas Schäffer • Frederic L. P. Gabriel • Hans-Peter E. Kohler • \\ Philippe F. X. Corvini
}

Received: 1 April 2011 /Revised: 14 June 2011 / Accepted: 15 June 2011 /Published online: 14 July 2011

(C) Springer-Verlag 2011

\begin{abstract}
In silico analysis of nucleotide sequences flanking the recently found hydroquinone dioxygenase in Sphingomonas sp. strain TTNP3 revealed a gene cluster that encodes a hydroquinone catabolic pathway. In addition to the two open-reading frames encoding the recently characterized hydroquinone dioxygenase, the cluster consisted of six open-reading frames. We were able to express the three open-reading frames, $h q d C, h q d D$, and $h q d E$, and demonstrated that the three gene products, $\mathrm{HqdC}, \mathrm{HqdD}$, and HqdE had 4-hydroxymuconic semialdehyde dehydrogenase, maleylacetate reductase, and intradiol dioxygenase activity, respectively. Surprisingly, the gene cluster showed similarities to functionally related clusters found in members of the $\beta$ - and $\gamma$-proteobacteria rather than to those found in other members of the genus Sphingomonas sensu latu.
\end{abstract}

Keywords Hydroquinone - Degradation · Sphingomonas . Nonylphenol · Bisphenol A

\footnotetext{
B. A. Kolvenbach $(\bowtie) \cdot H$. Dobrowinski $\cdot$ P. F. X. Corvini Institute for Ecopreneurship, School of Life Sciences, University of Applied Sciences Northwestern Switzerland,

Muttenz, Switzerland

e-mail: boris.kolvenbach@fhnw.ch
}

B. A. Kolvenbach · A. Schäffer

Institute for Environmental Research, Rheinisch-Westfälische

Technische Hochschule,

Aachen, Germany

J. Fousek $\cdot$ C. Vlcek

Institute of Molecular Genetics, Academy of Sciences of the Czech Republic,

Prague, Czech Republic

\section{Introduction}

Bisphenol A (BPA) and nonylphenol (NP) are well-known environmental contaminants that exert adverse effects on the reproductive system and the development of organisms (vom Saal and Hughes 2005; Soares et al. 2008). Both compounds have been widely detected in surface waters in concentrations up to several microgram per liter, i.e. levels that already may cause biological effects (Soares et al. 2008; Klecka et al. 2010; vom Saal and Hughes 2005; Raecker et al. 2011). Fortunately, under aerobic conditions, BPA and NP may both be degraded by various microorganisms (Kolvenbach et al. 2007; Gabriel et al. 2007a, 2008; Kang et al. 2006; Corvini et al. 2006b). Besides further restricting the use of BPA and nonylphenol polyethoxylates, optimization of biological wastewater treatment techniques, based on a better understanding of biodegradation mechanisms, may hence contribute to reduce current pollutant levels. We

\footnotetext{
J. Fousek $\cdot$ C. Vlcek

Centre for Applied Genomics,

Prague, Czech Republic

F. L. P. Gabriel

Institute of Clinical Chemistry and Laboratory Medicine,

University of Rostock,

Rostock, Germany

H.-P. E. Kohler

Swiss Federal Institute of Aquatic Science and Technology, Dübendorf, Switzerland

P. F. X. Corvini

School of the Environment, Nanjing University,

Nanjing, China
} 
recently have characterized an ipso-substitution pathway that is used by several sphingomonads, i.e., members of the genus Sphingomonas sensu latu, to degrade nonylphenols and bisphenol $\mathrm{A}$ and that yields hydroquinone as an intermediate (Gabriel et al. 2005b, 2007a, b); Corvini et al. 2006a; Kolvenbach et al. 2007.

Sphingomonads are frequently isolated from the environment as potent degraders of a wide range of xenobiotics, such as PAH (Zhao et al. 2008; Schuler et al. 2009), $\gamma-\mathrm{HCH}$ (Manickam et al. 2008), pentachlorophenol (Yang et al. 2006), herbicides, such as 2,4-D (Shimojo et al. 2009), isoproturone (Hussain et al. 2011), and alkylphenolic disruptors (Gabriel et al. 2005a; Sakai et al. 2007; Sasaki et al. 2005). Among bacteria isolated from the environment, sphingomonads have a special status as their genes show a relatively low degree of sequence homology with homologous genes from other Proteobacteria. This indicates that flow of genetic information between sphingomonads and other genera is restricted (Stolz 2009).

In sphingomonads, hydroquinone is formed as a metabolite during degradation of 4-nitrophenol and, as a minor metabolite, during that of $\gamma$-hexachlorohexane (Leung et al. 1997, 1999; Endo et al. 2005). The hydroquinone dioxygenases found in these strains are of the LinE or PcpA type and are encoded by a single open-reading frame (Miyauchi et al. 1999; Ohtsubo et al. 1999). In the corresponding gene clusters, the open-reading frame encoding for the hydroquinone dioxygenase is located near that of maleylacetate reductase, which is transcribed in the reverse direction. The two genes are separated by a sequence assigned to a putative LysR-type transcriptional regulator (Endo et al. 2005). Other hydroquinone dioxyenases have also been found clustered with sequences coding for glutathione Stransferases associated with upstream steps of the lindane degradation pathway (Nagata et al. 2006).

In $\beta$ - and $\gamma$-proteobacteria, hydroquinone was found as a metabolite in the degradation of 4-hydroxyacetophenone (Moonen et al. 2008) and 4-nitrophenol (Wei et al. 2010; Shen et al. 2010). The identified clusters contained open reading frames (putatively) coding for the two subunits of a heterotetrameric hydroquinone dioxygenase, a 4hydroxymuconic semialdehyde dehydrogenase, a maleylacetate reductase, an intradiol dioxygenase and a ferredoxin (Shen et al. 2010; Wei et al. 2010; Moonen et al. 2008; Zhang et al. 2009).

Recently, the hydroquinone dioxygenase from Sphingomonas sp. strain TTNP3 has been purified. Unlike all other hydroquinone dioxygenases identified in sphingomonads so far, the enzyme is an $\alpha_{2} \beta_{2}$ heterotetramer and is encoded by two open-reading frames ( $h q d A$ and $h q d B$; Kolvenbach et al. 2011).

Here, we present the partial characterization of a Sphingomonas sp. strain TTNP3 gene cluster involved in hydroquinone degradation. Besides containing the genes coding for the hydroquinone dioxygenase, i.e. $h q d A, h q d B$, and additional open-reading frames encoding functional enzymes of the hydroquinone degradation pathway. Remarkably, in terms of arrangement and sequence of genes, the TTNP3 hydroquinone dioxygenase cluster resembles functionally related clusters contained in $\beta$ - and $\gamma$-proteobacteria and is dissimilar to those in $\alpha$-proteobacteria, such as sphingomonads.

\section{Materials and methods}

Genomic data and sequence accession numbers

Partial genomic data of Sphingomonas sp. strain TTNP3 has been as described elsewhere (Kolvenbach et al. 2011). The nucleotide and amino acid sequences reported here have been deposited at GenBank under accession number JF440299.

\section{Chemicals}

Tris, nicotinamide adenine dinucleotide (NAD) and the reduced salt of NAD (NADH) were obtained from Applichem (Axonlab, Switzerland). A technical nonylphenol mixture, hydroquinone, catechol, and hydroxyhydroquinone were obtained from Sigma (Switzerland).

In silico analysis of genomic sequences of Sphingomonas sp. strain TTNP3

Open-reading frames were identified using the GeneMark. hmm for Prokaryotes algorithm, version 2.4 (Lukashin and Borodovsky 1998). Comparisons of amino acid or nucleotide sequences were performed with the respective Basic Local Alignment Search Tool (BLAST) programs on the National Center for Biotechnology Information (NCBI) website (http://www.ncbi.nlm.nih.gov/; Altschul et al. 1997).

Bacterial strains and culture conditions for Sphingomonas sp. strain TTNP3

Sphingomonas sp. strain TTNP3 (Table 1) (deposited at BCCM under accession number LMG 21268) was grown on Standard I Medium as described previously (Corvini et al. 2004). Cells were harvested at an $\mathrm{OD}_{550}$ of about 3.0. If not stated otherwise, enzymatic activity was induced by addition of $0.5 \mathrm{mM}$ technical grade nonylphenol $16 \mathrm{~h}$ prior to harvesting. Cultures were then centrifuged at $4,500 \times \mathrm{g}$ for $15 \mathrm{~min}$ and resuspended in $50 \mathrm{mM}$ Tris buffer $(\mathrm{pH} \mathrm{7.0)}$ at $4^{\circ} \mathrm{C}$. The washing procedure was repeated twice before the 
Table 1 Bacterial strains and plasmids used in this study

\begin{tabular}{lll}
\hline $\begin{array}{l}\text { Strains and } \\
\text { plasmids }\end{array}$ & Characteristics & $\begin{array}{c}\text { Source or } \\
\text { reference }\end{array}$ \\
\hline $\begin{array}{l}\text { Strains } \\
\begin{array}{l}\text { Sphingomonas sp. } \\
\text { strain TTNP3 }\end{array}\end{array}$ & $\begin{array}{c}\text { Wild-type, nonylphenol } \\
\text { degrader }\end{array}$ & $\begin{array}{c}\text { Tanghe et } \\
\text { al. (1999) }\end{array}$ \\
$\begin{array}{l}\text { E. coli } \\
\text { DH5 } \alpha\end{array}$ & Amplification of plasmids & NEB \\
BL21 & Expression strain & Invitrogen \\
Plasmids & T-A clone vector & \\
pGEM-T easy & pGEM derivative bearing hqdC & This work \\
pGEM-hqdC & pGEM derivative bearing hqdD & This work \\
pGEM-hqdD & pGEM derivative bearing hqdE & This work \\
pGEM-hqdE & pGEM derivative bearing & This work \\
pGEM-con & the Promega control insert & \\
\hline
\end{tabular}

cells were resuspended to attain a dry weight concentration of $33 \mathrm{mg} / \mathrm{mL}$ and stored at $-20^{\circ} \mathrm{C}$.

Cloning and expression of hqdC, hqdD, and hqdE from Sphingomonas sp. strain TTNP3

$h q d C, h q d D$, and $h q d E$ were amplified from Sphingomonas sp. strain TTNP3 by colony polymerase chain reaction (PCR) using high-fidelity polymerase Elongase (Invitrogen, Switzerland) and the primers listed in Tables 2 and 3. Products were purified by electrophoresis and subsequent extraction from agarose gels with the Nucleospin Extract II extraction kit (Macherey-Nagel, Switzerland), before adenylation and ligation into the pGEM-T easy vector (Promega, USA) by means of T4 DNA ligase (New England Bioscientific via Bioconcept, Switzerland) to yield plasmids designated pGEM-hqdC, pGEM-hqdD, and pGEM-hqdE, respectively. As a control, the control insert enclosed in the pGEM-T easy kit was ligated into the vector, designated pGEM-con (Table 1). Plasmids were individually transformed into 5-alpha high efficiency competent Escherichia coli (NEB, USA) for plasmid amplification. The correct orientation of the respective insert in the vector was confirmed by PCR using the M13 reverse primer as forward primer (as it is oriented opposite to the desired insert) and the respective reverse primer used for amplification of the insert. Clones were grown on SOC medium containing $100 \mathrm{mg} / \mathrm{L}$ ampicillin, and plasmids were recovered by the Qiaprep Spin Miniprep Kit (Qiagen, Switerland) and transformed into BL21-DE3 pLysS competent $E$. coli (Invitrogen via Lubioscience, Switzerland). For protein expression, cells were grown on LB medium containing $100 \mathrm{mg} / \mathrm{L}$ ampicillin and $34 \mathrm{mg} / \mathrm{L}$ chloramphenicol to an $\mathrm{OD}_{600}$ of 0.6 and induced for $4 \mathrm{~h}$ at $37^{\circ} \mathrm{C}$ by addition of $1 \mathrm{mM}$ IPTG, before harvesting the cells by centrifugation for $15 \mathrm{~min}$ at $4,500 \times \mathrm{g}$. Overexpression was verified by sodium dodecyl sulfate-polyacrylamide gel electrophoresis (SDS-PAGE) analysis.

Preparation of cell extracts and enzyme assays

Thawed cells of Sphingomonas sp. strain TTNP3 were disrupted by means of sonication on ice $(8 \mathrm{~min}$ at $60 \%$ intensity, $0.6 \mathrm{~s} / \mathrm{s}$ duty cycle using a Labsonic $\mathrm{M}$ sonicator by B. Braun Biotech, equipped with a $3 \mathrm{~mm}$ probe).

E. coli cells were harvested after induction, washed twice with Tris buffer $\left(50 \mathrm{mM}, \mathrm{pH} 7.5\right.$ at $\left.4^{\circ} \mathrm{C}\right)$ and disrupted by sonication on ice $(30 \mathrm{~s}$ at $60 \%$ intensity, $0.6 \mathrm{~s} / \mathrm{s}$ duty cycle using a Labsonic $\mathrm{M}$ sonicator by $\mathrm{B}$. Braun Biotech, equipped with a 3-mm probe). The obtained crude extracts were separated from cells and debris by centrifugation $(21,500 \times g$ for $15 \mathrm{~min})$.

Both formation and degradation of 4-hydroxymuconic semialdehyde in the wild-type strain were monitored photometrically at $320 \mathrm{~nm}$ (Spain and Gibson 1991). Of the sample, $35 \mu \mathrm{L}$ (either crude cell extract or $50 \mathrm{mM}$ Tris buffer at $\mathrm{pH} 7.0$ for abiotic controls) was added to $280 \mu \mathrm{L}$ of Tris buffer and reactions were started by adding $35 \mu \mathrm{L}$ of a freshly prepared solution of hydroquinone in Tris buffer (final hydroquinone concentration of $100 \mu \mathrm{M}$ ).

4-Hydroxymuconic semialdehyde dehydrogenase activity of 4-hydroxymuconic semialdehyde dehydrogenase (HqdC)

Table 2 Primers used in this study

\begin{tabular}{llll}
\hline Primer & Oligo sequence & Purpose & Position in the sequence \\
\hline hqdCF & ATGGCCCTCGACGACC & Amplification of hqdC & $4153-4168$ \\
hqdCR & TCAGCGCTTGTAGAACGG & Amplification of hqdC & $5632-5649$ \\
hqdDF & ATGCAGGATTTCATTTACTGCGG & Amplification of hqdD & $5655-5677$ \\
hqdDR & TCATGATGCCGGACGCTC & Amplification of hqdD & $6696-6713$ \\
hqdEF & ATGAAAGGTGCGATCTTCCC & Amplification of hqdE & $6710-6729$ \\
hqdER & TTATGCTCCAGCCAAGCG & Amplification of hqdE & $7520-7537$ \\
M13 reverse & CAGGAAACAGCTATGAC & Screening for correctly oriented inserts & None \\
\hline
\end{tabular}




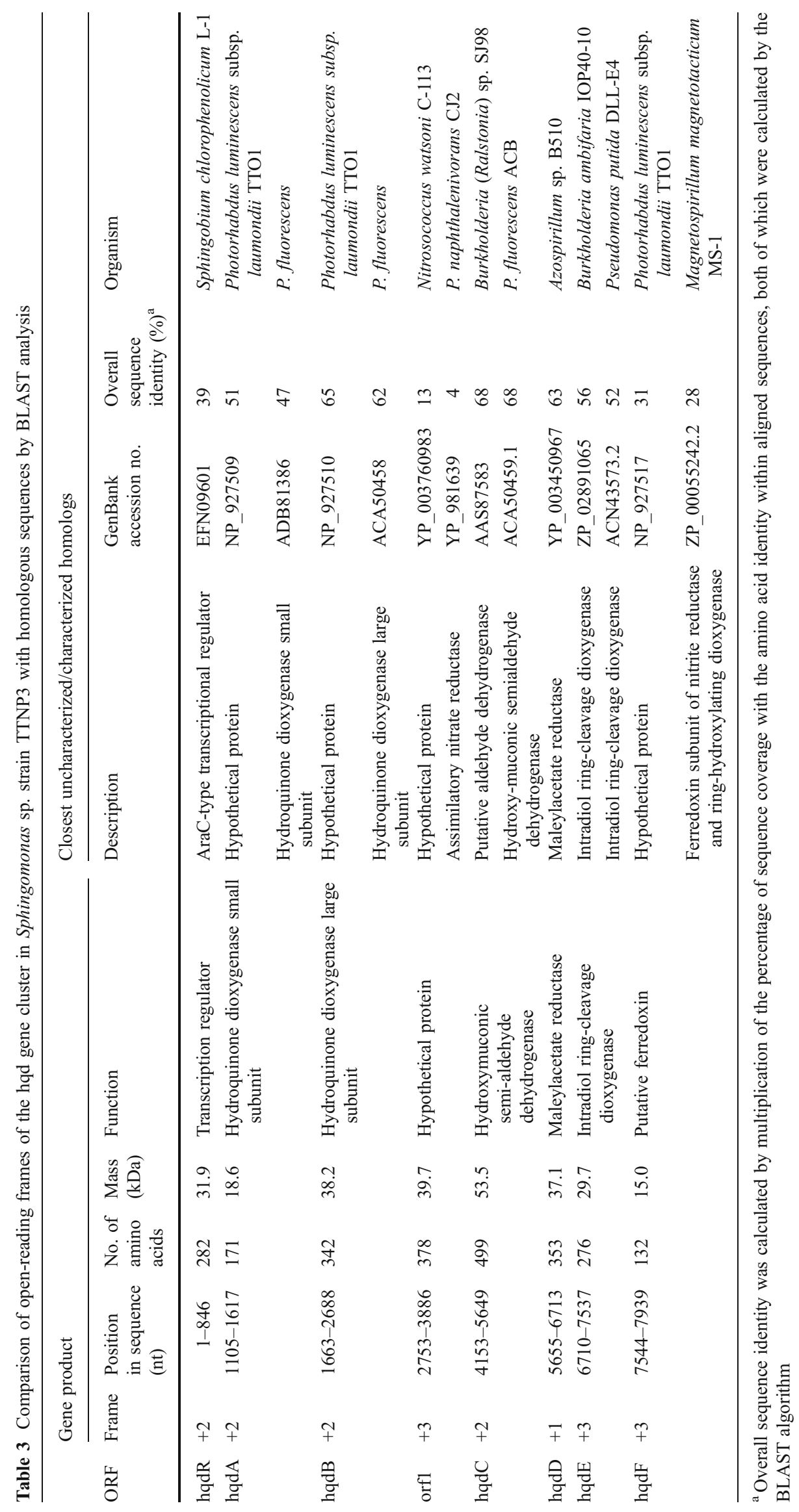


was assayed photometrically by monitoring the decrease of substrate concentration at $320 \mathrm{~nm}$, in addition to subsequent gas chromatography-mass spectrometry (GCMS) analysis as described below. Reaction mixtures contained $0.5 \mathrm{mM}$ NAD, $200 \mu \mathrm{M}$ 4-hydroxymuconic semialdehyde, and $175 \mu \mathrm{L}$ cell extract brought to a final volume of $350 \mu \mathrm{L}$ with $50 \mathrm{mM}$ Tris buffer (pH 7.0). Reactions were started by addition of 4-hydroxymuconic semialdehyde, which was freshly produced by incubation of purified hydroquinone dioxygenase from Sphingomonas sp. strain TTNP3 with $400 \mu \mathrm{M}$ hydroquinone for $10 \mathrm{~min}$. The purification of hydroquinone dioxygenase of Sphingomonas sp. strain TTNP3 has been recently described (Kolvenbach et al. 2011).

For maleylacetate reductase activity of $\mathrm{HqdE}$, reaction mixtures contained $2 \mathrm{mM}$ NADH, $0.5 \mathrm{mM}$ maleylacetate, and $175 \mu \mathrm{L}$ cell extract, brought to a total volume of $350 \mu \mathrm{L}$ with $50 \mathrm{mM}$ Tris buffer ( $\mathrm{pH}$ 7.0). Maleylacetate was freshly produced by hydrolysis of $5 \mathrm{mM}$ cisbutenolide in water containing $15 \mathrm{mM} \mathrm{NaOH}$ (Kaschabek and Reineke 1995). For HqdE, $175 \mu \mathrm{L}$ of cell extract and $140 \mu \mathrm{L}$ of $50 \mathrm{mM}$ Tris buffer ( $\mathrm{pH}$ 7.0) were incubated with $0.5 \mathrm{mM}$ hydroxyhydroquinone or catechol (both substrate solutions were prepared as $5 \mathrm{mM}$ stock solutions in water instantly before the experiment), respectively, before incubating for $30 \mathrm{~min}$ at room temperature. The samples incubated with catechol also contained $1 \mathrm{mM}$ of EDTA.

Cell extract of the strain bearing pGEMcon was used as a negative control for all enzyme assays.

After $30 \mathrm{~min}$ of incubation at room temperature, all reaction solutions for the respective enzyme assays were worked up for GC-MS analysis.

\section{Analytical methods}

Samples were acidified with a drop of $6 \mathrm{M} \mathrm{HCl}$ and extracted twice with two volumes of ethyl acetate; the organic phase was dried over $\mathrm{Na}_{2} \mathrm{SO}_{4}$ before evaporation under a gentle nitrogen stream. Extracts were redissolved in acetonitrile/N,O-bis(trimethylsilyl)trifluoroacetamide $(90: 10 v / v)$ for derivatization at $75^{\circ} \mathrm{C}$ for $15 \mathrm{~min}$. Samples were analyzed in an Agilent 7890A series gas chromatograph (Agilent Technologies, Basel, Switzerland) equipped with a Zebron ZB-5MS column, $(30 \mathrm{~m} \times 0.25 \mathrm{~mm}, 0.25 \mu \mathrm{m}$ film thickness, Phenomenex) coupled to an Agilent 5975 C series mass spectrometer. The mass selective detector was operated in the scan mode (mass range $m / z 50-600$ ) with an electron energy of $70 \mathrm{eV}$. The oven temperature program was $70^{\circ} \mathrm{C}$ for $3 \mathrm{~min}, 8^{\circ} \mathrm{C}$ per minute to $250^{\circ} \mathrm{C}$; the injector temperature was $200^{\circ} \mathrm{C}$; the interface temperature $280^{\circ} \mathrm{C}$. The injection volume was $1 \mu \mathrm{L}$ (split 1:30). The carrier gas was helium $(1 \mathrm{~mL} / \mathrm{min})$.
SDS-PAGE was carried out with $10 \%$ Tris-glycine minigels according to a standard protocol (Laemmli 1970) in a Mini-PROTEAN Tetra Cell (BioRad), using Precision plus unstained protein standards (Biorad).

\section{Results}

Hydroquinone metabolism in the wild-type strain

In degradation experiments with hydroquinone and crude extracts of Sphingomonas sp. strain TTNP3, we observed an initially rapid increase in absorption of the reaction mixture at $320 \mathrm{~nm}$. The increase came to a halt after about 2 min and was followed by a decrease, indicating that the putative 4-hydroxymuconic semialdehyde intermediate had been degraded to further metabolites. Crude cell extracts from uninduced cells had an initial apparent hydroquinone dioxygenase specific activity of $5 \mathrm{mU} / \mathrm{mg}$ protein, whereas activities of extracts from cells induced with $0.5 \mathrm{mM}$ hydroquinone and $0.5 \mathrm{mM}$ technical nonylphenol were 96 and $297 \mathrm{mU} / \mathrm{mg}$, respectively. The apparent degradation rates of 4-hydroxymuconic semialdehyde in the later course of the reaction were $0.6,2.5$, and $3.1 \mathrm{mU} / \mathrm{mg}$ protein for the uninduced, hydroquinone-induced, and nonylphenolinduced cells, respectively. GC-MS analysis of trimethyl silylated samples of the reaction mixture taken after $15 \mathrm{~min}$ of incubation led us to identify 4-hydroxymuconic semialdehyde and 3-oxoadipate as products. 4-Hydroxymuconic semialdehyde produced several chromatographic peaks that corresponded to different conformational isomers with mass spectra similar to one another and consistent with literature data (Miyauchi et al. 1999). 3-Oxoadipate was identified by the mass spectrum of its N,O-bis(trimethylsilyl) trifluoroacetamide (BSTFA)-derivatized form (Rieble et al. 1994).

Catechol and hydroxyhydroquinone metabolism in the wild-type strain

Crude extract of strain TTNP3 contained enzyme activities for turnover of catechol as well as hydroxyhydroquinone. GC-MS analysis of trimethyl silylated samples of incubation mixtures with catechol led to the detection of two meatbolites. One of the metabolites showed a retention time and a mass spectrum identical to those of the trimethyl silylated derivative of authentic cis,cis-muconic acid (Table 4) and the other metabolite showed a retention time and a mass spectrum identical to those of the trimethyl silylated derivative of authentic 3oxoadipate (Table 4; Rieble et al. 1994). GC-MS analysis of trimethyl silylated samples of incubation mixtures with hydroxyhydroquinone also showed the formation of two metabolites. Here, one showed the retention time and 
Table 4 Mass spectra of identified metabolites

\begin{tabular}{lll}
\hline $\begin{array}{l}\text { Compound, TMS } \\
\text { derivatized }\end{array}$ & $\begin{array}{l}\text { Retention } \\
\text { time(s) min }\end{array}$ & Mass spectrum $m / z$ (relative intensity) \\
\hline Maleylacetate & 20.6 & $\begin{array}{c}374(0.8), 359(2.6), 315(1.8), 257(67), 241(1.3), 197(4.9), 153 \\
(11), 147(100), 123(4.4), 109(3.2), 95(4.5), 75(44), 73(45)\end{array}$ \\
3-Oxoadipate & 20.9 & $\begin{array}{c}376(3.8), 361(23), 317(3.7), 286(11), 259(8), 243(14), 231(13), \\
169(58), 147(84), 73(100)\end{array}$ \\
cis,cis-Muconate & 18.5 & $286(2.6), 271(9), 243(3.0), 169(100), 147(87), 73(83)$ \\
\hline
\end{tabular}

respective mass spectrum identical to that of the trimethyl silylated derivative of maleylacetate (Table 4) and the other one had a mass spectrum identical to that reported for trimethylsilylated 3-oxoadipate.

\section{hqd Gene cluster of Sphingomonas sp. strain TTNP3}

In silico analysis of the sequences flanking $h q d A$ and $h q d B$, which encode the small and large subunit of hydroquinone dioxygenase in Sphingomonas sp. strain TTNP3, revealed the presence of a gene cluster that contained, besides $h q d A$ and $h q d B$, six additional openreading frame (ORF; see Fig. 1). BLAST searches for four of these ORF ( $h q d C, h q d D, h q d E$, and $h q d F$ ) revealed $68 \%, 63 \%, 56 \%$, and $31 \%$ sequence similarities, respectively, to nucleic acid sequences coding for enzymes functionally related to hydroquinone degradation (Table 3). The ORF termed $h q d R$ bore sequence similarities to a putative AraC-type transcriptional regulator from Sphingobium chlorophenolicum L-1 (39\% sequence identity), and the one termed orfl showed $4 \%$ sequence identity to an assimilatory nitrate reductase from Polaromonas naphthalenivorans strain CJ2 (Table 3).

Qualitative determination of enzyme activities in cell extract of E. coli BL21-DE3 overexpressing $h q d C$, $h q d D$, and $h q d E$

Incubation of cell extract of E. coli BL21-DE3 expressing $\mathrm{HqdC}$ with 4-hydroxymuconic semialdehyde and $\mathrm{NAD}^{+}$ led to a decrease of absorption at $320 \mathrm{~nm}$ in the incubation mixture. GC-MS analysis of trimethylsilylated samples of

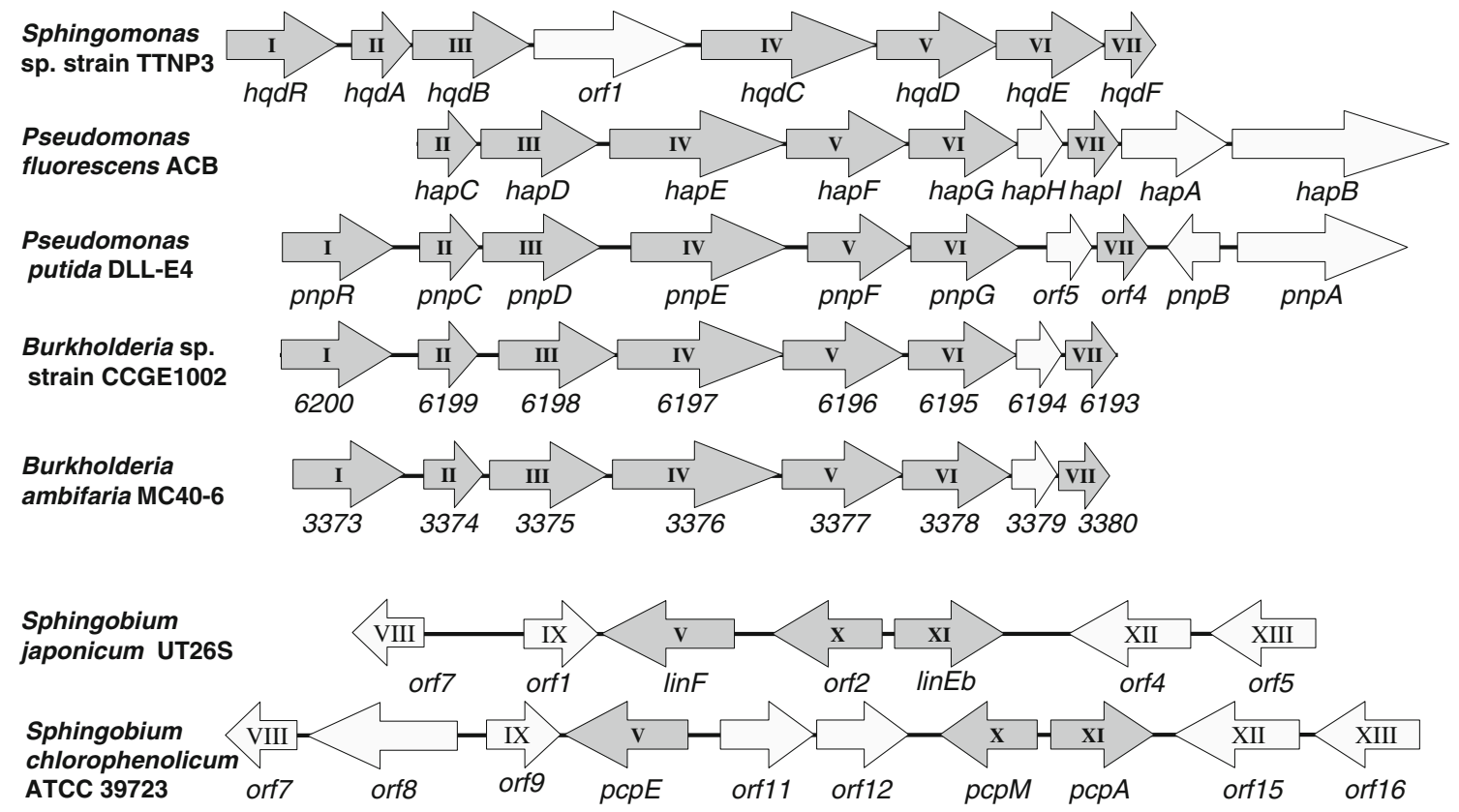

Fig. 1 Organization of the hqd gene cluster on a 8.0-kb fragment of the genome of Sphingomonas sp. strain TTNP3 (for detailed explanation, see Table 3), aligned with the hap gene cluster of $P$. fluorescens strain ACB (GenBank accession number AF355751), the pnp gene cluster of Pseudomonas putida DLL-E4 (GenBank accession number FJ376608) and putative hydroquinone degradation gene clusters of Burkholderia sp. strain CCGE1002 (NCBI reference sequence NC 014119.1; chromosome 3; e.g., 6200 corresponds to BC1002_6200) and Burkholderia ambifaria MC40-6 (NCBI reference sequence NC_010552.1; chromosome 2; 3373 corresponds to BamMC406_3373, e.g.). Organization of clusters attributed to HQ degradation in two sphingomonad strains are shown for comparison, i.e., Sphingobium japonicum UT26 (NCBI reference sequence AB177985) and Sphingobium chlorophenolicum ATCC 39723 (NCBI reference sequence AF512952). Roman numbers gene homologies, dark gray arrows genes attributed to hydroquinone degradatino, and light gray arrows other genes. The genes indicated with $I$ and $X$ code for (putative) transcriptional regulators 


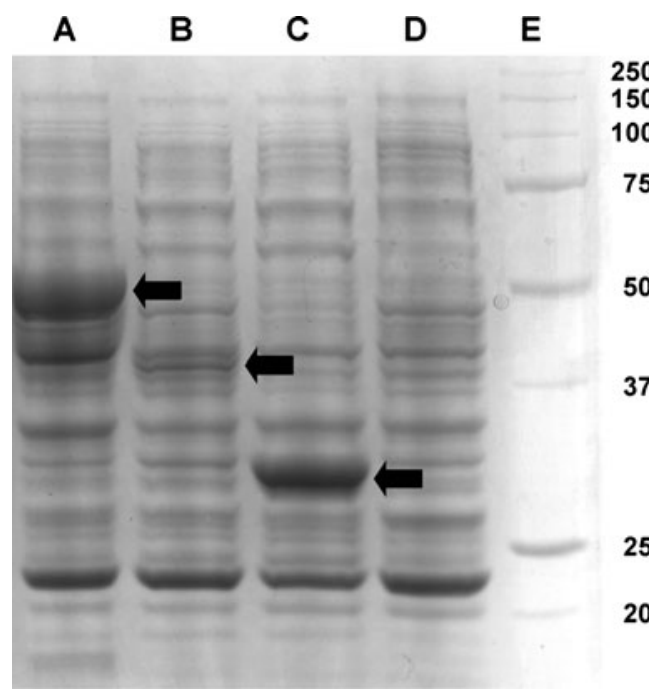

Fig. 2 SDS-PAGE analysis of cell extracts of $E$. coli strains after induction with $1 \mathrm{mM}$ IPTG. $A, B, C$, and $D$ show cell extract of the strains bearing, pGEM-hqdC, pGEM-hqdD, pGEM-hqdE, and pGEMcon, respectively; $E$ marker proteins. Arrows indicate the bands attributed to the respective heterologously expressed enzymes

such incubation mixtures revealed the formation of a peak with respective retention time and mass spectrum corresponding to that of trimethylsilylated maleylacetate. Addition of NADH and maleylacetate to cell extract of the
E. coli strain expressing maleylacetate reductase (HqdD) yielded a product whose mass spectrum was identical to that of the 3-oxoadipate product detected in crude cell extracts of Sphingomonas sp. strain TTNP3. GC-MS analyses showed that cell extract of the E. coli strain expressing HqdE was capable of degrading both catechol and hydroxyhydroquinone to metabolites with retention times and mass spectra identical to those of cis,cis-muconic acid and maleylacetate, respectively. Expression of $h q d C, h q d D$, and $h q d E$, respectively, has been verified by SDS-PAGE (Fig. 2).

\section{Discussion}

Previous incubations of crude cell extracts of Sphingomonas sp. strain TTNP3 with the substrates NP and BPA, respectively, showed formation of hydroquinone as an intermediate. Hydroquinone was further degraded to 4hydroxymuconic acid semialdehyde by a hydroquinone dioxygenase (Kolvenbach et al. 2011). In this work, we could show that 4-hydroxymuconic semialdehyde is transformed to maleylacetate and then to 3-oxoadipate in subsequent steps (Fig. 3). We could also show that the DNA sequences surrounding those sequences coding for the subunits of the already characterized hydroquinone dioxygenase form a gene cluster containing several open reading a

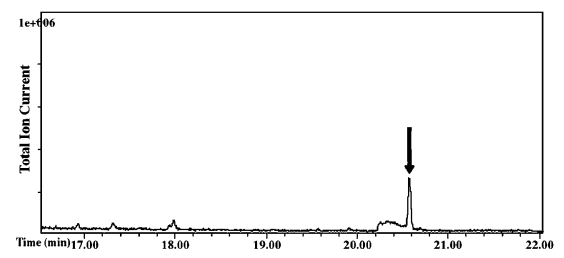

d

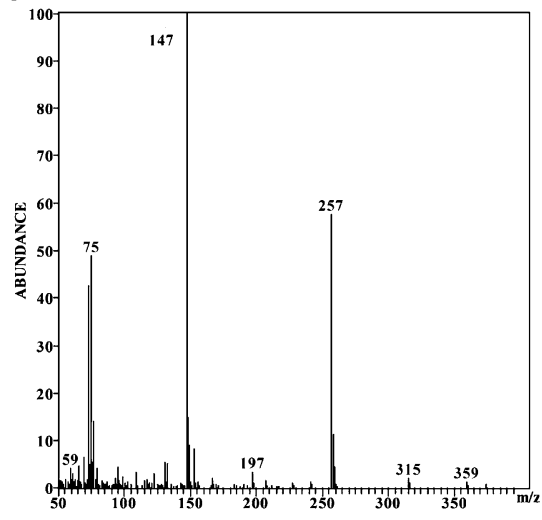

b

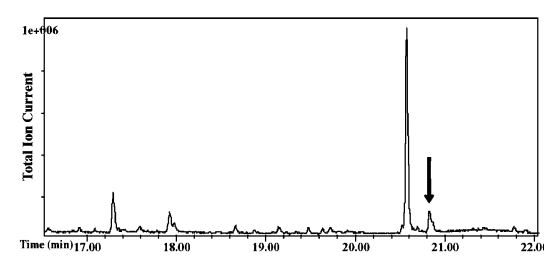

e

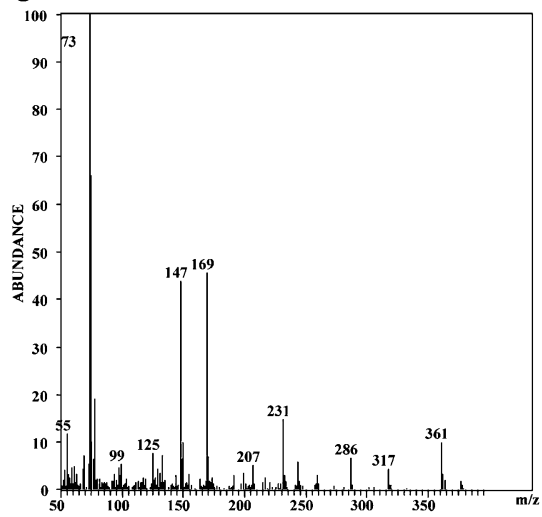

C

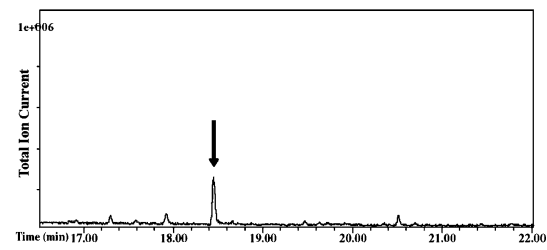

f

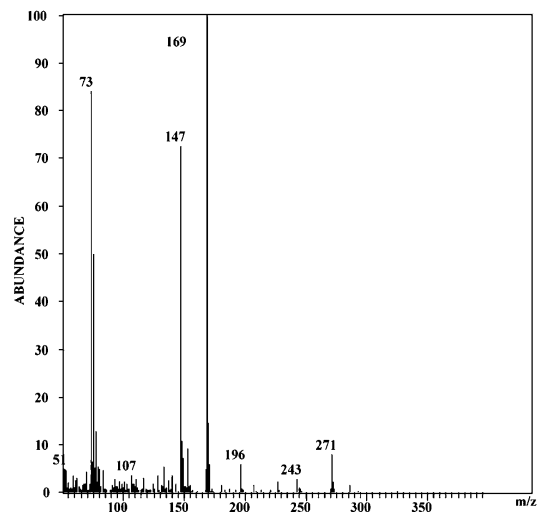

Fig. 3 Chromatograms of incubations with cell extracts of E. coli strains and mass spectra of metabolites formed by enzymes encoded in the $h q d$ gene cluster. a GC-MS chromatogram of BSTFA-derivatized extract of the incubation of HqdC with 4-hydroxymuconic semialdehyde and NAD, derivatized maleylacetate is indicated by the arrow; b GC-MS chromatogram of BSTFA-derivatized extract of the incubation of HqdD with maleylacetate and NADH, derivatized 3oxoadipate is indicated by the arrow; c GC-MS chromatogram of BSTFA-derivatized extract of the incubation of HqdE with catechol, derivatized cis,cis-muconate is indicated by the arrow; d mass spectrum of maleylacetate from a; e mass spectrum of 3-oxoadipate from $\mathbf{b}$; f mass spectrum of cis, cis-muconate from $\mathbf{c}$ 
Fig. 4 Proposed pathway for the degradation of hydroquinone in Sphingomonas sp. strain TTNP3. Enzyme activities that were successfully annotated to open-reading frames in the hqd cluster are labeled with the respective names. Open-reading frames that were functionally verified in this work are framed

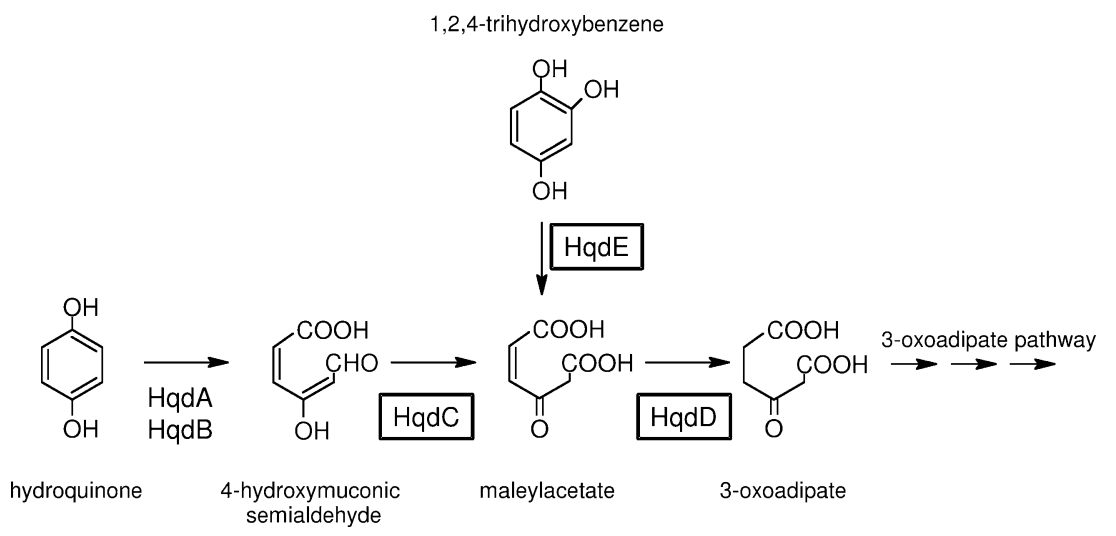

frames possibly associated to hydroquinone degradation in Sphingomonas sp. strain TTNP3. For two open reading frames, i.e. $h q d C$ and $h q d D$, this association could be shown.

Furthermore, we demonstrated hydroquinone dioxygenase activity to be inducible by hydroquinone and technical NP, although it is possible that induction by NP was actually mediated by the hydroquinone intermediate formed during degradation of NP (Corvini et al. 2006a). We observed lower hydroquinone dioxygenase activities in extracts of cells grown in the presence of hydroquinone than in extracts of cells grown with technical NP. However, further research is needed to establish whether induction after incubation with NP may also be caused by the hydroquinone intermediate formed during degradation of $\mathrm{NP}$, as NP is transformed by a constitutively expressed ipsohydroxylase (Corvini et al. 2006a).

This contrast between the inducibility of hydroquinone dioxygenase and constitutive expression of nonylphenol ipso-hydroxylase, the enzyme catalyzing the initial step in NP degradation, is a further example of the complex regulation mechanisms operating in sphingomonads (Stolz 2009). Whether or not the genes $h q d C$, hqdD, hqdE, and $h q d F$ are co-transcribed with $h q d A$ and $h q d B$ will need to be examined in further experiments.

Three of the ORFs in the hqd gene cluster of Sphingomonas sp. strain TTNP3 were cloned and heterologously expressed in E. coli. We confirmed that the putative HqdC and $\mathrm{HqdD}$ held the annotated function (see Fig. 4). The E. coli clone expressing HqdE was able to cleave both catechol and hydroxyhydroquinone to the respective intradiol ringcleavage products, whereas the control strain only containing the vector with a control insert was not. In the wild-type strain, incubations with catechol also led to the formation of small amounts of 3-oxoadipate, indicative of the strain's ability to further metabolize the ring cleavage product. As hydroxyhydroquinone was not found as a metabolite in incubations of hydroquinone with cell extract of Sphingomonas sp. strain TTNP3, the role of HqdE in the degradation of hydroquinone still remains unclear in this strain.
As $40-60 \%$ sequence identity have been shown to be sufficient for protein function transfer (for enzymes, thirdlevel to full enzyme commission numbers could be inherited within this threshold, as shown by Addou et al. (2009)), it is tempting to speculate that the ORF termed $h q d R$ may be involved in the expression regulation of the cluster. However, its exact role remains elusive. The sequence-derived gene product showed $39 \%$ and $38 \%$ amino acid identity to putative AraC-type transcription regulators found in the shotgun genome sequence $S$. chlorophenolicum strain L-1 (GenBank accession number EFN09601.1) and in the genome sequence of Sphingobium japonicum strain UT26S (GenBank accession number BAI95789.1), respectively. Both putative regulators are located upstream of putative intradiol ring-cleavage dioxygenases and are transcribed in the same direction as the dioxygenases. Nevertheless, their exact role has not been elucidated yet.

The possible gene product of $h q d F$ was identified by sequence identity as a putative [2Fe-2S] ferredoxin, with $28 \%$ overall sequence identity to a known ferredoxin (Table 3). It was recently shown that a group of 16 ferredoxins belonging to ring-hydroxylating enzymes had quite homogenous amino acid sequences, with sequence identities of as little as 29\% (Kweon et al. 2008). Previously, it was shown that this type of ferredoxins might participate in the reactivation of catechol 2,3-dioxygenases (Hugo et al. 1998, 2000; Polissi and Harayama 1993) after suicide deactivation by halogenated or methylated catechol derivatives (Bartels et al. 1984; Cerdan et al. 1994). An analog reactivation mechanism has been recently proposed for heterotetrameric hydroquinone dioxygenases such as the ones identified in Sphingomonas sp. strain TTNP3 and Pseudomonas fluorescens strain ACB (Kolvenbach et al. 2011; Moonen et al. 2008). Future studies will show if $h q d F$ codes for a ferredoxin involved in reactivation of hydroquinone dioxygenase.

As the amino acid sequence of the translated gene product of orfl showed only weak similarities to known 
proteins (i.e., 4\%, compare Table 3), its function in Sphingomonas sp. strain TTNP3 remains unknown.

In terms of arrangement of open-reading frames, the hqd gene cluster of Sphingomonas sp. strain TTNP3 resembles gene clusters associated with hydroquinone degradation of Pseudomonas (Moonen et al. 2008; Shen et al. 2010; Wei et al. 2010) and putative gene clusters of Burkholderia strains (Fig. 1) and does not resemble gene clusters associated with chlorohydroquinone degradation in downstream pathways of pentachlorophenol and lindane degrading sphingomonads (Cai and Xun 2002; Nagata et al. 2007). Moreover, BLAST searches for the gene products of the hqd cluster in all but one case (HdqR) showed that the sequences had higher similarities to sequences from nonsphingomonads than to those form other sphingomonads (Table 3). We conclude that strain TTNP3 may have acquired the hqd cluster at least partially from $\beta$-or $\gamma$-proteobacteria by horizontal gene transfer (Table 4).

Acknowledgments BAK and FLPG were funded by the Swiss National Science Foundation grant SNF-200021-120547. JF and CV were funded by the EC Grant Agreement 265946. We thank Dr. Stefan Kaschabek (University Freiberg) for generously providing a sample of cis-butenolide.

\section{References}

Addou S, Rentzsch R, Lee D, Orengo CA (2009) Domain-based and family-specific sequence identity thresholds increase the levels of reliable protein function transfer. J Mol Biol 387(2):416-430

Altschul SF, Madden TL, Schäffer AA, Zhang J, Zhang Z, Miller W, Lipman DJ (1997) Gapped BLAST and PSI-BLAST: a new generation of protein database search programs. Nucleic Acids Res 25(17):3389-3402. doi:10.1093/nar/25.17.3389

Bartels I, Knackmuss H-J, Reineke W (1984) Suicide inactivation of catechol 2,3-dioxygenase from Pseudomonas putida mt-2 by 3halocatechols. Appl Environ Microbiol 47(3):500-505

Cai M, Xun L (2002) Organization and regulation of pentachlorophenol-degrading genes in Sphingobium chlorophenolicum ATCC 39723. J Bacteriol 184(17):4672-4680. doi:10.1128/jb.184.17.4672-4680.2002

Cerdan P, Wasserfallen A, Rekik M, Timmis KN, Harayama S (1994) Substrate specificity of catechol 2, 3-dioxygenase encoded by TOL plasmid pWW0 of Pseudomonas putida and its relationship to cell growth. J Bacteriol 176(19):6074-6081

Corvini PFX, Vinken R, Hommes G, Schmidt B, Dohmann M (2004) Degradation of the radioactive and non-labelled branched $4\left(3^{\prime}, 5^{\prime}-\right.$ dimethyl 3'-heptyl)-phenol nonylphenol isomer by Sphingomonas TTNP3. Biodegradation 15(1):9-18

Corvini PFX, Hollender J, Ji R, Schumacher S, Prell J, Hommes G, Priefer U, Vinken R, Schaffer A (2006a) The degradation of alphaquaternary nonylphenol isomers by Sphingomonas sp. strain TTNP3 involves a type II ipso-substitution mechanism. Appl Microbiol Biotechnol 70(1):114-122. doi:10.1007/s00253-005-0080-0

Corvini PFX, Schaffer A, Schlosser D (2006b) Microbial degradation of nonylphenol and other alkylphenols - our evolving view. Appl Microbiol Biotechnol 72(2):223-243. doi:10.1007/s00253-0060476-5
Endo R, Kamakura M, Miyauchi K, Fukuda M, Ohtsubo Y, Tsuda M, Nagata Y (2005) Identification and characterization of genes involved in the downstream degradation pathway of gammahexachlorocyclohexane in Sphingomonas paucimobilis UT26. J Bacteriol 187(3):847-853. doi:10.1128/jb.187.3.847-853.2005

Gabriel FLP, Giger W, Guenther K, Kohler H-PE (2005a) Differential degradation of nonylphenol isomers by Sphingomonas xenophaga Bayram. Appl Environ Microbiol 71(3):1123-1129. doi:10.1128/aem.71.3.1123-1129.2005

Gabriel FLP, Heidlberger A, Rentsch D, Giger W, Guenther K, Kohler HPE (2005b) A novel metabolic pathway for degradation of 4-nonylphenol environmental contaminants by Sphingomonas xenophaga Bayram: ipso-hydroxylation and intramolecular rearrangement. J Biol Chem 280(16):15526-15533. doi:10.1074/jbc.M413446200

Gabriel FLP, Cyris M, Giger W, Kohler HPE (2007a) ipsoSubstitution: a general biochemical and biodegradation mechanism to cleave alpha-quaternary alkylphenols and bisphenol A. Chem Biodivers 4(9):2123-2137

Gabriel FLP, Cyris M, Jonkers N, Giger W, Guenther K, Kohler HPE (2007b) Elucidation of the ipso-substitution mechanism for sidechain cleavage of alpha-quaternary 4-nonylphenols and 4-tbutoxyphenol in Sphingobium xenophagum Bayram. Appl Environ Microbiol 73(10):3320-3326. doi:10.1128/aem.02994-06

Gabriel FLP, Routledge EJ, Heidlberger A, Rentsch D, Guenther K, Giger W, Sumpter JP, Kohler HPE (2008) Isomer-specific degradation and endocrine disrupting activity of nonylphenols. Environ Sci Technol 42(17):6399-6408. doi:10.1021/es800577a

Hugo N, Armengaud J, Gaillard J, Timmis KN, Jouanneau Y (1998) A novel [2Fe-2S] ferredoxin from Pseudomonas putida $\mathrm{mt} 2$ promotes the reductive reactivation of catechol 2,3-dioxygenase. J Biol Chem 273(16):9622-9629

Hugo N, Meyer C, Armengaud J, Gaillard J, Timmis KN, Jouanneau Y (2000) Characterization of three XylT-like [2Fe-2S] ferredoxins associated with catabolism of cresols or naphthalene: evidence for their involvement in catechol dioxygenase reactivation. J Bacteriol 182(19):5580-5585. doi:10.1128/jb.182.19.5580-5585.2000

Hussain S, Devers-Lamrani M, El Azhari N, Martin-Laurent F (2011) Isolation and characterization of an isoproturon mineralizing Sphingomonas sp. strain SH from a French agricultural soil. Biodegradation 22(3):637-650

Kang J-H, Katayama Y, Kondo F (2006) Biodegradation or metabolism of bisphenol A: from microorganisms to mammals. Toxicology 217(2-3):81-90

Kaschabek SR, Reineke W (1995) Maleylacetate reductase of Pseudomonas sp. strain B13: specificity of substrate conversion and halide elimination. J Bacteriol 177(2):320-325

Klecka GM, Naylor CG, Staples CA, Losey B (2010) Occurrence of nonylphenol ethoxylates and their metabolites in municipal wastewater treatment plants and receiving waters. Water Environ Res 82:447-454

Kolvenbach B, Schlaich N, Raoui Z, Prell J, Zuhlke S, Schaffer A, Guengerich FP, Corvini PFX (2007) Degradation pathway of bisphenol A: does ipso substitution apply to phenols containing a quaternary alpha-carbon structure in the para position? Appl Environ Microbiol 73(15):4776-4784

Kolvenbach BA, Lenz M, Benndorf D, Rapp E, Vlcek C, Fouzek J, Gabriel FLP, Kohler H-PE, Schäffer A (2011) Purification and characterization of hydroquinone dioxygenase from Sphingonomas sp. strain TTNP3. AMB Express 1:8

Kweon O, Kim S-J, Baek S, Chae J-C, Adjei MA, Baek D-H, Kim Y-C, Cerniglia CE (2008) A new classification system for bacterial Rieske non-heme iron aromatic ring-hydroxylating oxygenases. BMC Biochem 9:11. doi:10.1186/1471-2091-9-11

Laemmli UK (1970) Cleavage of structural proteins during the assembly of the head of bacteriophage T4. Nature 227(5259):680-685 
Leung KT, Tresse O, Errampalli D, Lee H, Trevors JT (1997) Mineralization of $p$-nitrophenol by pentachlorophenol-degrading Sphingomonas spp. FEMS Microbiol Lett 155(1):107-114

Leung KT, Campbell S, Gan Y, White DC, Lee HT, Trevors J (1999) The role of the Sphingomonas species UG30 pentachlorophenol4-monooxygenase in $p$-nitrophenol degradation. FEMS Microbiol Lett 173(1):247-253

Lukashin AV, Borodovsky M (1998) GeneMark.hmm: new solutions for gene finding. Nucleic Acids Res 26(4):1107-1115

Manickam N, Reddy MK, Saini HS, Shanker R (2008) Isolation of hexachlorocyclohexane-degrading Sphingomonas sp. by dehalogenase assay and characterization of genes involved in $\gamma-\mathrm{HCH}$ degradation. J Appl Microbiol 104(4):952-960

Miyauchi K, Adachi Y, Nagata Y, Takagi M(1999) Cloning and sequencing of a novel meta-cleavage dioxygenase gene whose product is involved in degradation of gamma-hexachlorocyclohexane in Sphingomonas paucimobilis. J Bacteriol 181(21):6712-6719

Moonen MJH, Kamerbeek NM, Westphal AH, Boeren SA, Janssen DB, Fraaije MW, van Berkel WJH (2008) Elucidation of the 4hydroxyacetophenone catabolic pathway in Pseudomonas fluorescens ACB. J Bacteriol 190(15):5190-5198. doi:10.1128/jb.01944-07

Nagata Y, Kamakura M, Endo R, Miyazaki R, Ohtsubo Y, Tsuda M (2006) Distribution of $\gamma$-hexachlorocyclohexane-degrading genes on three replicons in Sphingobium japonicum UT26. FEMS Microbiol Lett 256(1):112-118. doi:10.1111/j.1574-6968.2005.00096.x

Nagata Y, Endo R, Ito M, Ohtsubo Y, Tsuda M (2007) Aerobic degradation of lindane ( $\gamma$-hexachlorocyclohexane) in bacteria and its biochemical and molecular basis. Appl Microbiol Biotechnol 76(4):741-752

Ohtsubo Y, Miyauchi K, Kanda K, Hatta T, Kiyohara H, Senda T, Nagata Y, Mitsui Y, Takagi M (1999) PcpA, which is involved in the degradation of pentachlorophenol in Sphingomonas chlorophenolica ATCC39723, is a novel type of ring-cleavage dioxygenase. FEBS Lett 459(3):395-398

Polissi A, Harayama S (1993) In vivo reactivation of catechol 2,3dioxygenase mediated by a chloroplast-type ferredoxin: a bacterial strategy to expand the substrate specificity of aromatic degradative pathways. EMBO J 12(8):3339-3347

Raecker T, Thiele B, Boehme RM, Guenther K (2011) Endocrine disrupting nonyl- and octylphenol in infant food in Germany: considerable daily intake of nonylphenol for babies. Chemosphere 82(11):1533-1540

Rieble S, Joshi DK, Gold MH (1994) Purification and characterization of a 1, 2, 4-trihydroxybenzene 1, 2-dioxygenase from the basidiomycete Phanerochaete chrysosporium. J Bacteriol 176(16):4838-4844

Sakai K, Yamanaka H, Moriyoshi K, Ohmoto T, Ohe T (2007) Biodegradation of bisphenol $\mathrm{A}$ and related compounds by Sphingomonas sp. strain BP-7 isolated from seawater. Biosci Biotechnol Biochem 71(1):51-57. doi:10.1271/bbb.60351

Sasaki M, Maki J, Oshiman K, Matsumura Y, Tsuchido T (2005) Biodegradation of bisphenol A by cells and cell lysate from
Sphingomonas sp. strain AO1. Biodegradation 16(5):449-459. doi:10.1007/s10532-004-5023-4

Schuler L, Jouanneau Y, Ní Chadhain S, Meyer C, Pouli M, Zylstra G, Hols P, Agathos S (2009) Characterization of a ringhydroxylating dioxygenase from phenanthrene-degrading Sphingomonas sp. strain LH128 able to oxidize benz $[a]$ anthracene. Appl Microbiol Biotechnol 83(3):465-475. doi:10.1007/s00253009-1858-2

Shen W, Liu W, Zhang J, Tao J, Deng H, Cao H, Cui Z (2010) Cloning and characterization of a gene cluster involved in the catabolism of $p$-nitrophenol from Pseudomonas putida DLL-E4. Bioresource Tech 101(19):7516-1522

Shimojo M, Kawakami M, Amada K (2009) Analysis of genes encoding the 2,4-dichlorophenoxyacetic acid-degrading enzyme from Sphingomonas agrestis 58-1. J Biosci Bioeng 108(1):56-59

Soares A, Guieysse B, Jefferson B, Cartmell E, Lester JN (2008) Nonylphenol in the environment: a critical review on occurrence, fate, toxicity and treatment in wastewaters. Environ Int 34 (7): 1033-1049

Spain JC, Gibson DT (1991) Pathway for biodegradation of $p$ nitrophenol in a Moraxella sp. Appl Environ Microbiol 57 (3):812-819

Stolz A (2009) Molecular characteristics of xenobiotic-degrading sphingomonads. Appl Microbiol Biotechnol 81(5):793-811. doi:10.1007/s00253-008-1752-3

Tanghe T, Dhooge V, Verstraete W (1999) Isolation of a bacterial strain able to degrade branched nonylphenol. Appl Environ Microbiol 65(2):746-751

vom Saal FS, Hughes C (2005) An extensive new literature concerning low-dose effects of bisphenol A shows the need for a new risk assessment. Environ Health Perspect 113(8):926-933. doi: $10.1289 /$ ehp. 7713

Wei Q, Liu H, Zhang J-J, Wang S-H, Xiao Y, Zhou N-Y (2010) Characterization of a para-nitrophenol catabolic cluster in Pseudomonas sp. strain NyZ402 and construction of an engineered strain capable of simultaneously mineralizing both paraand ortho-nitrophenols. Biodegradation 21(4):575-584

Yang C-F, Lee C-M, Wang C-C (2006) Isolation and physiological characterization of the pentachlorophenol degrading bacterium Sphingomonas chlorophenolica. Chemosphere 62 (5):709-714

Zhang J-J, Liu H, Xiao Y, Zhang X-E, Zhou N-Y (2009) Identification and characterization of catabolic para-nitrophenol 4monooxygenase and para-benzoquinone reductase from Pseudomonas sp. strain WBC-3. J Bacteriol 191(8):2703-2710. doi:10.1128/jb.01566-08

Zhao H-P, Wang L, Ren J-R, Li Z, Li M, Gao H-W (2008) Isolation and characterization of phenanthrene-degrading strains Sphingomonas sp. ZP1 and Tistrella sp. ZP5. J Hazard Mater 152 (3):1293-1300 